returned to the plot. A good way to get rid of carbon dioxide is to use water to build up soil organic matter by farming the desert, and to restrict drainage in some areas so as to make peat - if that can be managed without making methane. It is surely legitimate to wonder whether it will ever be practical to make carbon-based roads and buildings instead of liberating carbon dioxide by making cement.

Hillel has a pleasant scepticism. He suggests that the menace of spreading deserts has been exaggerated, as is the harm done by goats. Goats, like people, create problems when too numerous. But people cause most trouble because of their greed, stupidity and unwilling ness to use existing knowledge; goats, by contrast, are difficult to control because of their intelligence. For our convenience, we need a strain of goats that retain the remarkable digestive system of current types, but that are as stupid as sheep. Several other interesting research problems, aimed at giving the world a form more congenial to us, are discussed by Hillel or will come to mind when reading this stimulating book.

N. W. Pirie is at the AFRC Institute of Arable Crops Research, Rothamsted Experimental Station, Harpenden, Hertfordshire AL5 2JP, UK.

\section{Bad behaviour}

\section{Jeffrey Mervis}

Impure Science: Fraud, Compromise and Political Influence in Scientific Research. By Robert Bell. Wiley: 1992. Pp. 301. \$22.95 (US and Canada only).

As examples of misconduct in science mount, it is natural for observers to try to weave common threads through them. But it is damnably difficult to find useful similarities among situations that range from the arid Rift Valley of Ethiopia to the most modern of university laboratories, and from the clanging assembly lines of a defence contractor to the hushed meetings of a scientific advisory panel.

Such is the problem that confronts Robert Bell, an economist at Brooklyn College, City University of New York. Bell wants desperately to say something important about his subject, and he is constantly imploring the reader to see the 'big picture' in his descriptions of misconduct. But he never quite manages himself to draw that picture.

Bell seems prepared to jettison the consensus definition of scientific fraud falsification, fabrication and plagiarism of data - in favour of another terrible triumvirate more in tune with his politi- cal beliefs: 'big science', corporate support, and anything involving the US military establishment. It is an unhappy choice of targets, not because they are blameless, but rather because picking on them sheds so little light on the real causes of misconduct or on any potential solutions.

Bell explains that he has deliberately chosen cases from widely varying fields to show how pervasive is the stain of misconduct on the corpus of science. Yet one is left with the uncomfortable feeling that his selection process was arbitrary, reflecting more his personal prejudices and the availability of public source material than any real links between cases or concern for their larger relevance. How else to explain the lengthy treatment of the sad case involving Jon Kalb, a geologist working on prehistoric sites in Ethiopia who was unfairly blacklisted by the National Science Foundation (NSF) after baseless rumours of his being an agent for the CIA were raised during a review of his grant proposal? Or the political fight that ensued after the NSF awarded a five-year, $\$ 25$ million grant for an engineering earthquake centre to the University of Buffalo rather than to the University of California, Berkeley?

It took Kalb, who wound up with $\$ 20,000$ and an apology from the NSF, more than 10 years to prove that he had been wronged, and his diligence uncovered a hidden filing system that the NSF has since abandoned. Bell quotes liberally from Kalb's files, but the best he can do by way of a conclusion is to say that "scientists must speak up when they feel that their proposals have been treated unfairly". Who would disagree?

In the case of the earthquake centre, Bell makes the hardly surprising discovery that politics plays a role in the awarding of large grants. And his conviction that the centre should have been built in California - "the best scientists were not funded, while people of lesser achievement were funded" places him on very shaky ground indeed. $\mathrm{He}$ further claims, without substantiation, that the NSF pressured the National Academy of Sciences to restrain its criticism of a study of earthquake research that a US senator from California had convinced his congressional colleagues to fund as part of an unsuccessful campaign to reverse the NSF's original decision. This time his conclusion is not only weak, but also illogical: "If large science projects are not free of political influence, how can we expect smaller, less visible projects to be decided fairly and objectively?"

Such opinions could perhaps be excused if the author had marshalled them to prescribe a strong cure. Alas, he does not. His primary solution is to give

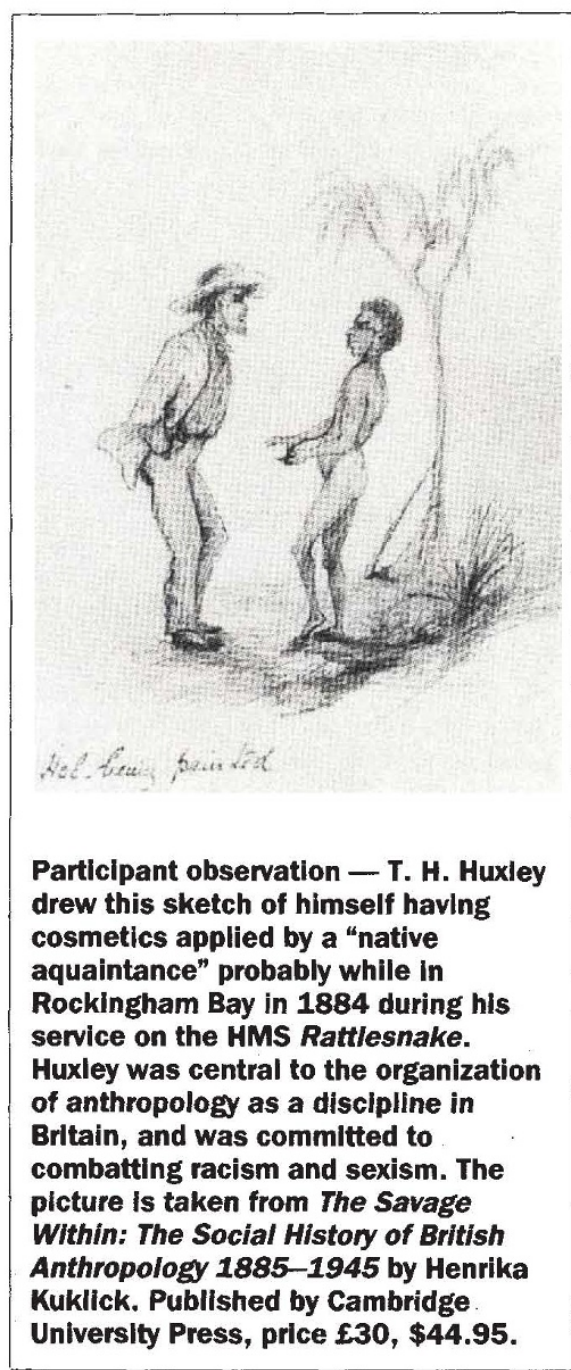

whistle-blowers more incentive to speak out and more protection when they do, and to let the courts resolve scientific disputes. Even if one believes that the legal system is capable of meting out justice in cases of misconduct, it is hard to imagine how the verdicts could be used by the vast number of scientists who, in Bell's mind, need to be kept on the straight and narrow. He also suggests that those involved in obtaining federal monies for their institutions - from the president of a university to the principal research investigator - should be excluded from any inquiries into alleged misconduct on the grounds that they are compromised by a desire to perpetuate the present system. If that practice were followed, few scientists and administrators would be left to investigate misconduct, or to help other, 'purer' souls to carry out the necessary work.

An effective way to deal with allegations of misconduct must be found if science hopes to retain its favoured position as an enterprise worthy of public support. Unfortunately, appropriate remedies are not to be found here.

Jeffrey Menis is news editor of Nature. 